liquors. In the analytical work, silver chloride was reduced to silver in a current of hydrogen, and the atomic weight of " ordinary" chlorine compared with that from the meteorite. Had the result shown a difference in atomic weight, then one could have been confident that the chlorine was not of terrestrial origin. But the results were identical within I part in 2000 , which was not outside the estimated experimental error. They were never published, because of the uncertainty as to the true source of this " meteoritic" chlorine.

It will be of interest to learn how Drs. Harkins and Stone have reassured themselves as to the extra-terrestrial origin of the meteoritic chlorine studied in their careful investigation.

Princeton University,

$$
\text { Alan W. C. Menzies. }
$$

October ro.

The Spectrum of $\mathrm{Si}^{+}$(Once Ionised Silicon).

Prof. A. Fowler has recently shown that the spectrum of $\mathrm{Si}^{+}$is similar in constitution to that of $\mathrm{Al}$, that is, consists of doublets having $2 p_{2}, 2 p_{1}$, as the highest terms. A number of lines, ascribed by Fowler to $\mathrm{Si}^{+}$, remain, however, well outside his scheme of classification, and some of these can be arranged in a group of quartets.

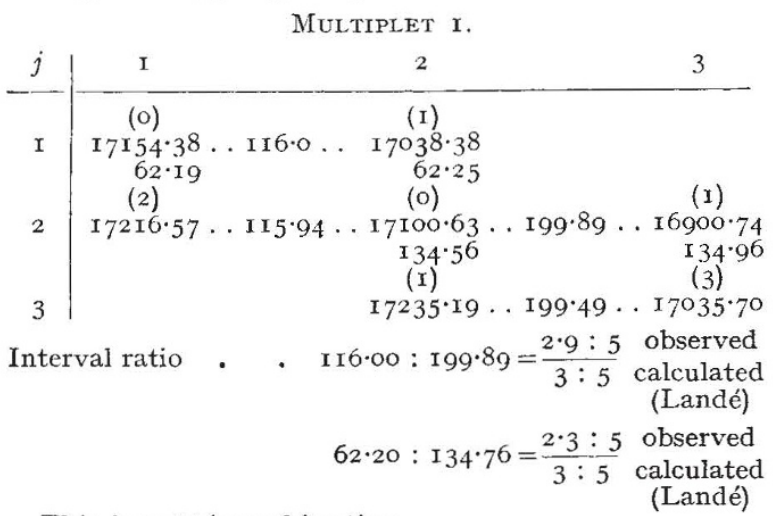

This is a $p p^{\prime}$-combination.

The intensity rule is only roughly obeyed.

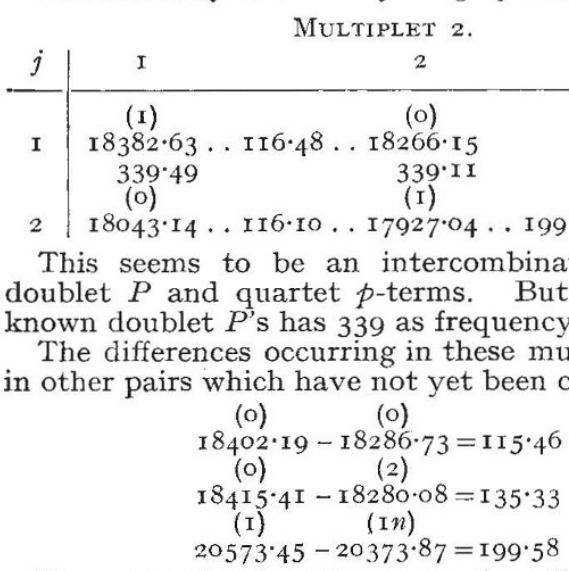

The group having the successive differences I99 and II 6 correspond to $p$-terms of a quartet series. Evidently a quartet series is possible for $\mathrm{Si}^{+}$, but it is only feebly developed under the usual methods of excitation. Without more data on the spectrum of $\mathrm{Si}^{+}$, it is not possible to find out more information on the point.

Allahabad University. Meghnad SaHa.
A Slow Process Method of Cyanide Fumigation for the Control of White-Fly in Tomato Houses.

EXPERIMENTS have shown that it is possible to generate hydrocyanic acid gas from a mixture consisting of 3 parts by weight of powdered sodium bicarbonate and I part by weight of high grade sodium cyanide ( 98 per cent. purity) for the purpose of fumigating tomato houses in the control of whitefly (Trialeurodes vaporariorum, Westw.).

The mixture is scattered on the dry paths of the houses at the rate of one ounce to every Iooo cubic feet space. The results show that mortality for adult fly is as great as that obtained where the gas is generated quickly from sodium cyanide and sulphuric acid in jars, but the percentage mortality for the scale stages is slightly higher in the latter method.

Economically the slow generation obtains practically as good a control as the quick method, and has great advantages in the saving of labour, and in minimising risk of scorching to plants which are grown soft. Whereas one man is required to each house in jar cyaniding, a large block of houses can be fumigated by one man when using the mixture described. The same precautions are necessary for the plants as in the case of jar cyaniding, but there is greater safety in fumigating by the slow process on windy nights. It is not advisable, however, to fumigate during heavy rain in leaky houses.

EDWARd R. SPEyer. O. OWEN

Experimental and Research Station, Cheshunt, Herts.

\section{Retrograde Metamorphosis.}

UNDER this denomination is understood the stepback from the normal state of an animal to that of a more primitive one. I was undergoing the strong sun-cure in Grado, an island in the Adriatic Sea, where the full sun shines for weeks together, with only slight interruptions, exposing to it the naked skin from morning until evening during the whole day. Belonging to the fair type, my body was only in some parts covered with spare hair. After some time perfectly new, very fine hair was formed on all parts of the body, and after the lapse of five weeks there was a remarkably thick cover of fine, very light hair even on those parts of the body where there was not a trace before, to prevent the body, which became dark red-brown, from being burnt. This observation has been made by me repeatedly for fifteen years, but it is not easy for others to repeat it. BOHUSLAV BRAUNER.

Charles' (Bohemian) University, Prague, October 7 .

\section{Prof. Andrew Gray.}

Dr. Alexander Russell's memoir of Prof. Andrew Gray, which appeared in NATURE of October 24, will be read with sympathetic interest by Prof. Gray's many friends. I must be one of the oldest of them surviving, for I was Gray's fellow-student in my uncle's natural philosophy class in Glasgow in the session $1874-75$, in which he carried off the second prize and I the fifth. From my knowledge of him at that time and since, I am able to appreciate the accuracy of Dr. Russell's notice, with the exception of one small error of date. Prof. Gray succeeded my uncle (Lord Kelvin) on his resignation of the natural philosophy chair in I899, not after his death in 1907 .

22 Wentworth Place, JAMEs Thomson.

Newcastle-upon-Tyne October 25.

NO. 2922 , vOL. I I 6 ] 